\title{
Exploring the link between more negative osmotic potential and ryegrass summer performance
}

\author{
L.V.Y. WEERARATHNE ${ }^{1}$, W. DONG ${ }^{2}$, M. NIE ${ }^{2}$, Y. WANG ${ }^{2}$, I.F. LOPEZ ${ }^{1}$ and C. MATTHEW ${ }^{1}$ \\ ${ }^{1}$ School of Agriculture and Environment, PN433 Massey University, PB 11-222, \\ Palmerston North 4442, New Zealand \\ ${ }^{2}$ Ningxia University, 489 He Lan Shan West Rd, Yinchuan, China 750021 \\ vishnaweerarathne@gmail.com
}

\begin{abstract}
This paper outlines recent research studying withinpopulation variation in selected New Zealand perennial ryegrass cultivars, for traits related to tolerance of summer moisture deficit. Two clonal replicates of 220 genotypes from 'Grasslands Nui' (Nui, $\mathrm{n}=50$ ), 'Grasslands Samson' (Samson, $\mathrm{n}=80$ ), and 'Trojan' $(\mathrm{n}=90)$ were exposed to 1 month of moisture deficit challenge, with plant water relations measurements performed to evaluate putative drought-response mechanisms. Water use of individual genotypes ranged from $<100$ to $>1000 \mathrm{~g}$ water/g DM indicating large within-population variation for this trait. Mean water use efficiency (WUE) was for Nui, Samson, and Trojan, respectively, $424 \pm 16,412 \pm 10$, and $319 \pm 9$ g water/g DW $(\mathrm{P}<0.001)$, suggesting that commercial plant breeding may have indirectly reduced water use in modern cultivars without specific focus on water relations. Principal component analysis indicated more negative osmotic potential may contribute to reduced water use while maintaining yield under water deficit, giving a potential focus for future breeding selection targeting summer water deficit tolerance.
\end{abstract}

Keywords: osmotic potential, perennial ryegrass, within-population variation, WUE

\section{Introduction}

Perennial ryegrass (Lolium perenne) has an acknowledged poor tolerance of summer drought, and consequently its effective use is limited to cool and wet areas of New Zealand (Cunningham et al. 1994; Lee et al. 2012). With New Zealand's heavy economic dependence on pastoral industries, recent industry research effort has been directed at perennial ryegrass improvement for summer yield (Easton et al. 2001; Stewart 2006; Lee et al. 2012). Summer yield is commonly limited by soil moisture deficit, with mean November-March evapotranspiration deficit for the years 2001-2009 for Southland, Waikato, and Manawatu regions being, respectively, 74, 180, and 258 $\mathrm{mm}$ (Matthew et al. 2012). Although improved summer performance has been addressed indirectly by the use of Spanish germplasm in breeding ryegrass programmes in New Zealand since the 1990s (Stewart 2006), the possibility of selecting directly for traits related to maintenance of productivity under water deficit has received little attention in New Zealand plant breeding, despite New Zealand's extensive ryegrass breeding effort since the 1930s.

The question of how to approach such research is not straight forward. It is known from international and New Zealand research that tall fescue and ryegrass varieties derived from North African germplasm tend to display a summer dormancy and deep-rootedness, but less negative osmotic potential during water deficit compared to varieties derived from European germplasm (Hussain 2013). However, historic efforts in South Australia to develop Mediterranean ryegrass varieties for release to the industry (Silsbury 1961), did not result in longer-term adoption. Similarly, Mediterranean ryegrass varieties tested in Canterbury were found to be lower-yielding than New Zealandbred varieties (Vartha 1975). Hussain (2013) examined relative merits of North African germplasm (cultivar 'Medea'), New Zealand germplasm (cultivar 'Grasslands Samson'), and introgression of Spanish (cultivar 'Tolosa') or meadow fescue (cultivar 'Matrix') germplasm into New Zealand germplasm, in a series of glasshouse studies and found that one prospect for future research was selection of elite genotypes displaying high water use efficiency within New Zealand germplasm (Figure 7.2 in Hussain 2013). Subsequently, He (2016) examined plant water relations traits of eight market-leading perennial ryegrass cultivars with or without irrigation, in a rainout shelter at Palmerston North, from December to March with observations in April on recovery after rewatering. Detailed data from clonal copies of 36 plant genotypes of eight ryegrass cultivars and a tall fescue cultivar in this study with and without irrigation and endophyte (432 plants in total), pointed to more negative osmotic potential as an important contributing trait to ryegrass summer water deficit tolerance, and 'Trojan' as a high-yielding cultivar with marked moisture deficit tolerance.

Based on results of these two studies, the present study was conducted to explore within-population 
variation in summer water deficit response of perennial ryegrass cultivars representing the Mangere ecotype, and modern New Zealand cultivars derived from the Mangere ecotype, without and with Spanish germplasm. These three cultivar categories form a timeseries of cultivar release dates, representing evolution of breeding practice as discussed by Stewart (2006).

Water deficit is defined by Begg \& Turner (1976) as any situation whenever water loss of a plant exceeds absorption. The degree of water deficit is quantified by measurement of traits such as leaf water potential (LWP), leaf relative water content (RWC) or leaf tissue osmotic potential (OP). As a reference value, permanent wilting point where plants lose water to the soil and die, is often considered to occur at a soil matric potential (SMP) of $-1.5 \mathrm{MPa}$ (Kirkham 2005). As an approximation SMP and LWP are likely to have similar values in many growing conditions, while OP will be more negative in order for plants to retain water and maintain turgor. A more negative OP means that plants are 'pulling harder' to extract water from dry soil. Further, the evapotranspiration cost of dry matter production (g water/g plant DW) can be referred to as 'water use efficiency' (WUE); and a lower numerical value for WUE represents 'improved' or 'higher' WUE. Plants possessing this trait can be considered 'good performers' and vice versa. The cultivar time-series was Nui/Samson/ Trojan. Specifically, the aims were to: (1) evaluate cultivar differences and heterogeneity within the cultivar release-date series for WUE and water relations traits (2) identify trait associations among the measured variables contributing to moisture deficit tolerance (or lack of) in particular genotypes, and (3) evaluate the potential for divergent selection for drought tolerance.

\section{Materials and methods}

\section{Experimental set up}

A pilot study in summer of 2014/2015 (Garcia 2015) used 27 plants each, of cultivars 'Grasslands Nui' (hereafter: 'Nui', N), 'Request' and 'Trojan', and tested a methodology to provide a moisture deficit challenge to single ryegrass plants over a period of about a month, and measure the water consumption and yield during water deficit. A fully watered treatment was not included as it would have halved the number of plant genotypes that could be tested in the experiment. The pilot study was deemed successful, and hence the larger study reported here was planned.

The present experiment was conducted in pots in a glasshouse environment at the Plant Growth Unit, Massey University, New Zealand $\left(40^{\circ} 22^{\prime} 41.22^{\prime \prime}\right.$, $175^{\circ} 36^{\prime} 48.73$ ”'E, $35 \mathrm{~m}$ a.s.1.), from June 2017 to January 2018. Single plants of the three cultivars
( $\mathrm{n}=50,80$, and 90 for Nui, Samson, and Trojan, respectively; 220 plants in total) were established from seed carrying the AR1 endophyte in June 2017. The rationale for these numbers was that 50 plants of a cultivar establishes a reliable population mean for traits of interest (Sartie et al. 2009), but the pilot experiment had shown a higher mean yield and improved WUE for 'Request' and 'Trojan', compared to 'Nui', so chances of finding elite plants with higher WUE would be enhanced by weighting the numbers towards the more recently released cultivars. The seeds were germinated in root trainers, and seedlings grown for 8 weeks to a size of $\geq 10$ tillers to facilitate division of plants into two clonal replicates (4-5 tillers each). Pots (sections of PVC water pipe $50 \mathrm{~cm}$ tall and 10 $\mathrm{cm}$ in diameter, with an end cap made from a double thickness of nylon horticultural shade mesh) were lined with tubular polythene plastic (with perforations at the bottom to allow drainage and aeration), and filled with fertilised Egmont black silt loam soil with water holding capacity (WHC) $>65 \%$, measured as mass of water/mass of soil, MW/MS). Pots were packed to a standard weight of $3.7-3.9 \mathrm{~kg}$ of air-dried soil/ pot. Two clonal replicates of the 220 genotypes to be tested were transplanted into experimental pots and arranged in a row-column design in the glasshouse. Pots were maintained at near field capacity for 6 weeks to allow tillering to $\geq 20$ tillers/pot and to ensure good root development. Plants were then defoliated to $5 \mathrm{~cm}$ above the soil surface and subjected to water deficit during the subsequent 'measurement' regrowth. The averaged maximum and minimum temperatures inside the glasshouse were 26 and $16{ }^{\circ} \mathrm{C}$, respectively. The relative humidity typically ranged from $60-80 \%$ and light intensity from $800-1000 \mu \mathrm{mol}$ photons $/ \mathrm{m}^{2} / \mathrm{s}$ at the canopy level at midday. Moisture deficit was imposed from mid-December 2017, starting with pots at field capacity (FC), and then reducing irrigation interval and volume progressively until pots reached $60 \%$ of FC (MW/MS 35\%), as determined by weighing pots individually on an electronic balance to $1 \mathrm{~g}$ precision. Thereafter, water was added twice weekly as required to keep pots at constant weight, and water use of each plant was recorded. For reference, samples of the soil used for filling pots, when tested on a pressure plate apparatus at $-0.01,-0.1$, and $-1.5 \mathrm{MPa}$ had gravimetric soil moisture of 66,46 , and $36 \%$, respectively. Plants were maintained under imposed drought until predawn leaf water potential (LWP) of randomly selected plants reached $-0.9 \mathrm{MPa}$, approximately 4 weeks after first reduction of water supply. At this point detailed measurements of plant water relations and yield traits were carried out over a 2 week time window, on the stressed plants as described below. 


\section{Measurements and analyses}

Measurements carried out included pre-dawn LWP (MPa), RWC (\%), and OP (MPa) as defined above; shoot dry weight (SDW, g) and root dry weight (RDW, $\mathrm{g}$ ); plant water use (PWU, g), and gravimetric soil moisture content at $40 \mathrm{~cm}$ below the soil surface (SMC, $\%)$. WUE was derived from the measured data as PWU/ $\mathrm{SDW}\left(\mathrm{g} \mathrm{H}_{2} \mathrm{O} / \mathrm{g} \mathrm{SDW}\right)$. The LWP was measured on the youngest fully expanded leaf of a representative tiller of each genotype, between 3 am and 6 am in the last week of the stress period using a Scholander's pressure chamber (Soil Moisture Equipment Crop., Santa Barbara. CA). Simultaneously, a second similar leaf from each genotype was snap frozen in liquid nitrogen and, stored at $-80^{\circ} \mathrm{C}$ for later determination of OP, using a Wescor HR-33T microvolt meter. RWC was calculated using the method of Barrs \& Weatherley (1962). Cumulative pot water use was recorded throughout the measurement regrowth period by summing pot weight loss and water added. Soil moisture (SMC) was determined by drying $300 \mathrm{~g}$ of soil from the $35-45 \mathrm{~cm}$ depth of each pot at $105^{\circ} \mathrm{C}$ for $>48$ hours. SDW samples were collected by clipping to $5 \mathrm{~cm}$ above the soil surface, the same height as at the previous cutting. Roots were harvested in two depth fractions (upper, 4-20 cm depth; lower, $20-50 \mathrm{~cm}$ depth) at a final destructive harvest at the end of the measurement period. Upper and lower fractions were summed to give RDW reported here. Both shoot and root samples were oven-dried separately at $80^{\circ} \mathrm{C}$ for 48 hours, and dry weights were taken. Regrowth was visually observed and scored (1 to 5) 2-3 days after defoliation. From the two replicates of 220 plants, averaged data were subjected to principal component analysis (PCA) in Minitab version 14 to establish drought-response mechanisms for selecting divergent groups of genotypes as good $(\mathrm{G})$ and bad (B) performers within cultivars $\mathrm{N}, \mathrm{S}$ and, T. Data were subjected to analysis of variance using Proc GLM) in SAS software Version 9.4 (SAS Institute Inc., Cary, NC, USA) to examine the cultivar and genotype-within-cultivar effects on test variables. No data transformations were required to meet ANOVA assumptions. Comparisons between means were done using Duncan's multiple range test. The time budget for these measurements was conservatively estimated at $>500$ hours and the moisture deficit challenge work was carried out over approximately 6 weeks by a team of 9 people to ensure timeliness of each measurement.

\section{Results}

\section{Cultivar and genotype effects}

There were significant cultivar differences for most traits measured, with cultivar 'Trojan' often separating from 'Samson' and 'Nui'. Similarly, genotype-withincultivar effects were seen for most test variables at $\mathrm{P}<0.0001$ (Table 1).

Trait associations and drought response mechanism Patterns of association between the traits were assessed by principal component analysis (PCA). In the PCA, $\mathrm{PC} 1$ and $\mathrm{PC} 2$, (accounting for $31.0 \%$ and $16.4 \%$ of data variance, respectively), both indicated a trait association between increased SDW, improved water use efficiency, and more negative osmotic potential. (Co-efficients for SDW, WUE, and OP were, respectively, 0.382, -0.390, and -0.294 for PC1, and $0.533,-0.532$ and -0.465 for PC2; note, a negative coefficient for WUE indicates less water use/g SDW). The fact that this three-way

Table 1 Measured trait means, and their statistical probabilities for cultivars 'Grasslands Nui' (Nui), 'Grasslands Samson' (Samson), and 'Trojan', and statistical probabilities for genotype effects within cultivars. The range among genotypes within cultivars appears in parentheses.

\begin{tabular}{|c|c|c|c|c|c|c|}
\hline \multirow[b]{2}{*}{ Trait } & \multicolumn{3}{|c|}{ Cultivar } & \multirow[b]{2}{*}{ SEM(Gen) } & \multirow[b]{2}{*}{$\mathbf{P}($ Gen) } & \multirow[b]{2}{*}{$P(C v)$} \\
\hline & Nui & Samson & Trojan & & & \\
\hline $\operatorname{SDW}(g)$ & $4.7(1.7-6.5)$ & $4.7(2.6-8.6)$ & $5.8(2.6-9.8)$ & 0.30 & $<0.0001$ & $<0.0001$ \\
\hline Total RDW (g) & $2.3(0.2-4.5)$ & $2.6(0.2-8.3)$ & $2.8(0.3-5.2)$ & 0.80 & $<0.0001$ & $<0.0001$ \\
\hline Bottom RDW (g) & $0.5(0.01-1.08)$ & $0.5(0.00-1.34)$ & $0.6(0.03-1.83)$ & 0.27 & $<0.0001$ & 0.09 \\
\hline RWC\% & $66.5(43.4-92.9)$ & $68.8(46.9-93.9)$ & $62.7(40.7-89.7)$ & 6.47 & $<0.0001$ & $<0.0001$ \\
\hline LWP (MPa) & $-0.83(-0.52$ to 1.29$)$ & $-0.81(-0.43$ to -1.38$)$ & $-0.86(-0.31$ to -1.41$)$ & 0.52 & $<0.0001$ & $<0.0001$ \\
\hline $\mathrm{OP}(\mathrm{MPa})$ & $-2.12(-1.27$ to -4.13$)$ & $-2.21(-1.43$ to -3.96$)$ & $-2.48(-1.36$ to -4.38$)$ & 2.89 & $<0.0001$ & $<0.0001$ \\
\hline PWU (g/pot) & $1894(1151-2502)$ & 1856 (789-2568) & 1719 (482-2381) & 222.29 & $<0.0001$ & $<0.0001$ \\
\hline WUE (g/g SDW) & $424(182-690)$ & $412(158-736)$ & $319(95-802)$ & 67.89 & $<0.0001$ & $<0.0001$ \\
\hline SMC (\%) & $41.0(33-60)$ & $40.4(31-56)$ & $40.4(26-55)$ & 7.21 & 0.06 & 0.8 \\
\hline
\end{tabular}

Trait abbreviations: SDW, Shoot dry weight; RDW, Root dry weight; LWP, Leaf water potential; OP, Osmotic potential; RWC, Relative water content (\%); PWU, Plant water use; WUE, Water-use efficiency (g water/g SDW); SMC, gravimetric soil moisture content at $30-40 \mathrm{~cm}$ depth, $\mathrm{P}(\mathrm{Cv})$, statistical probability of cultivar effect; $P(G e n)$, statistical probability of genotype-within-cultivar effect. SEM for comparing cultivars can be obtained by multiplying (SEM)Gen by 0.2 for 'Nui', 0.16 for 'Samson', and 0.15 for 'Trojan'. 


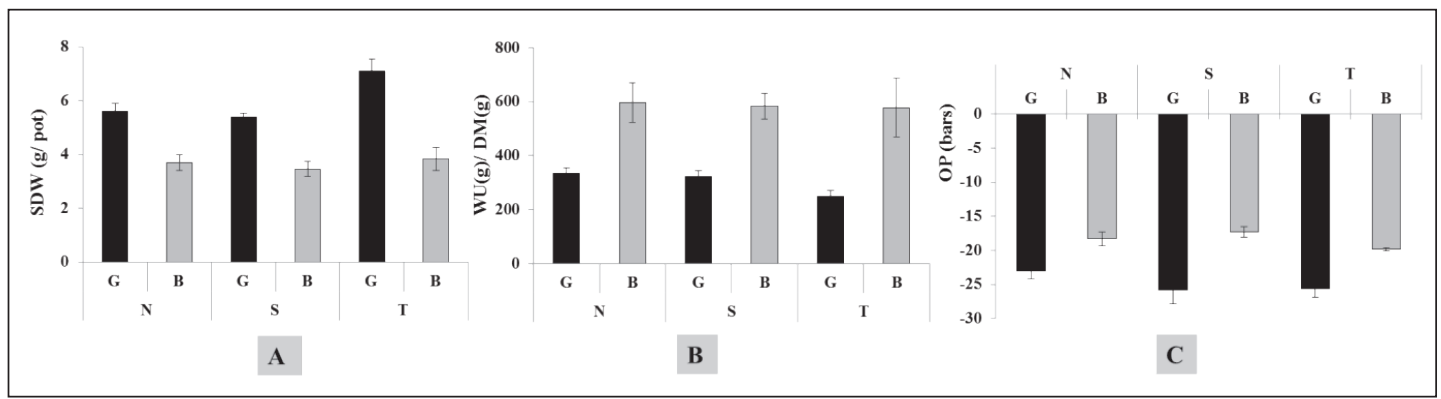

Figure 1 Means for: A) shoot dry weight (SDW); B) water use /gram of dry matter (WUE); and C) osmotic potential (OP), for divergently selected groups of genotypes within the population. Values for good performers $(\mathrm{G})$ are shown as black bars and bad performers (B) as grey bars. N, S, and T denote Nui, Samson, and Trojan, respectively.

trait association split into two PCs was indicated by other coefficients, as linked to plant hydration. For example, the coefficient for RWC was -0.336 for PC1 and +0.361 for $\mathrm{PC} 2$, and the coefficient for SMC was -0.345 for $\mathrm{PC} 1$ and +0.232 for PC2. Both PC1 and PC2 had positive coefficients for Bottom RDW ( 0.418 and 0.327 , respectively). Hence from the PCA it is clear that more negative OP is an important consideration for maintaining SDW in moisture deficit.

\section{Potential for divergent selection for WUE}

PCA and cluster analysis scores were used to identify the 25 best and 15 worst performing genotypes among the 220 genotypes tested. For these divergently selected groups of genotypes, SDW was $40 \%$ higher in good performers than bad performers (Figure 1A). Meanwhile WUE averaged for the best 25 genotypes was $278 \pm 12 \mathrm{~g} / \mathrm{g}$, while being $578 \pm 49 \mathrm{~g} / \mathrm{g}$ averaged for the 15 least efficient genotypes (Fig. 1B), thus displaying a more than two-fold difference in WUE between high- and low-water-use genotypes. In addition, the superior genotypes also displayed significantly more negative osmotic potential (Figure 1C). Among the 25 good performers there were 5 'Nui', 8 'Samson', and 12 'Trojan' genotypes, while among the 15 bad performers there were 8 'Nui', 5 'Samson', and 2 'Trojan' genotypes.

\section{Discussion}

The intention was for plants to be exposed to a moisture deficit challenge of sufficient duration and intensity to display their genetic potential for drought tolerance. Based on experience with the earlier series of experiments, a drying down period of $>3$ weeks to reach a LWP of approximately -1.0 MPa meets these criteria. To achieve this in potted plants, as in this experiment, needs careful attention to details such as soil volume: plant DW ratio and water holding capacity of the test soil. In this experiment, clipped plants at the start of dry-down are estimated to have had about 20 days' supply of soil-held, plant-available water. Soil water storage was boosted by choice of Egmont black silt loam with high water holding capacity as a soil medium for filling pots.

Data checks indicated good agreement between replicates. For example, the correlation between SDW values for the two replicates among the 220 genotypes tested was $0.943\left(\mathrm{~F}_{1,218}=1753 ; \mathrm{P}<0.001\right)$, while the correlation between replicates for WUE was 0.833 $\left(\mathrm{F}_{1,218}=495 ; \mathrm{P}<0.001\right)$. This engenders confidence that the test methodology can provide results that are sufficiently consistent for plant breeding purposes, if the traits measured are heritable, and if the moisture deficit challenge is sufficiently representative of field conditions faced by plants in summer. The consistency of genotype behaviour in different challenge events at different times clearly also needs to be established.

The conclusion from multivariate analysis that leaf tissue OP is important to WUE is also supported by intuitive inspection of results in Table 1. For example, across the cultivar time series, 'Nui' - 'Samson' 'Trojan', RDW:SDW ratio does not change, but OP becomes more negative and WUE improves (Table 1). A hypothesis from this observation for further study, is that more negative OP may lead to reduced evapotranspiration water loss from leaves. These conclusions are at variance with Blum (2009), who advises against selection for WUE, arguing that this approach will decrease yield, and that a range of physiological responses are usually induced in response to moisture deficit, and thus there is no single droughtresponse mechanism or trait that is highly correlated with yield under imposed drought (Ludlow \& Muchow 1990; Blum 2005; Tuberosa 2012), and therefore an obvious target trait for breeding selection.

It is salient to note that assuming plants dry the soil down to a similar soil water potential the yield increase in 'Trojan' compared to 'Nui', could be accounted for by increased water use efficiency alone. A similar result was also seen in the pilot study (Garcia 2015). 
Hence, the cultivar ranking 'Trojan' > 'Samson' > 'Nui' for WUE appears to indicate that 4 decades of plant breeder selection for yield has resulted in concurrent improvement in WUE, and that the intended improvement in tolerance of summer heat and moisture deficit through incorporating Spanish germplasm into modern ryegrass cultivars (Easton et al. 2001) has been achieved.

For plant breeding purposes, it will likely be necessary to discriminate between the plant types indicated by PC1 and PC2. The plant category described by PC2, where WUE and more negative OP are associated with better plant hydration and reduced depletion of $\mathrm{SMC}$, seems more promising. Turgor maintenance by more negative OP has been identified as an important adaptive trait for the survival of plants under drought events (Serraj \& Sinclair 2002; Blum 2005) including perennial ryegrass (Thomas \& Evans 1989; Thomas 1990). Osmotic adjustment was highlighted as a key determinant of yield of perennial ryegrass lines of diverse origin subjected to repeated drought cycles in a recent New Zealand experiment (Cyriac et al. 2018). However, its importance for yield has also been disputed with respect to many crop plants including perennial ryegrass (Thomas \& Evans 1989; Blum 2005). Also, most experiments where OA provided dubious benefits have been carried out in sand-based media with low WHC or under mild water deficit (LWP: -0.7 to -0.8 $\mathrm{MPa}$, OP: -1.7 to $-1.9 \mathrm{MPa}$ ), meaning that rapid drydown of potting media might not have allowed time for intracellular physiological adjustment, or less severe moisture deficit might not have fully stimulated it (Thomas \& Evans 1989). The present study involved more severe dehydration (LWP: -0.9 to $-1.3 \mathrm{MPa}$; OP: -2.0 to $-3.8 \mathrm{MPa}$ ), and a comparatively slow dry-down occurred as a result of the high WHC of the Egmont silt loam soil used. High WUE linked to more negative OP in this study was associated with an increase in RDW at depth in the soil profile (data not shown). This trait, together with more negative OP would provide for enhanced extraction of soil moisture and assist maintenance of cell turgor in perennial ryegrass (Cyriac et al. 2018). Improved root penetration in drought has been reported in previous studies for a large variety of crops (Blum 2005). Moreover, major solutes responsible for lowering OP in response to drought have been found to not reduce growth (Blum 2017).

\section{Conclusions}

This study tested a methodology for applying a moisture deficit challenge to single potted ryegrass plant, and measuring water relations traits, including WUE. Results indicate that under conditions tested, more negative leaf OP is linked to reduced water use and higher yield, and that improved summer WUE may underlie yield improvements in modern cultivars. Further experiments are under way to confirm the repeatability of these results and their relevance to ryegrass improvement programmes.

\section{ACKNOWLEDGEMENTS}

This work was supported by the T.R. Ellett Agricultural Research Trust and $\mathrm{PhD}$ Scholarship funding from Massey University. Authors are appreciative of the assistance given by the technical staff of the Plant Growth Unit, Massey University.

\section{REFERENCES}

Barrs, H.D.; Weatherley, P.E. 1962. A re-examination of the relative turgidity technique for estimating water deficits in leaves. Australian Journal of Biological Sciences 15: 413-428.

Begg, J.E.; Turner, N.C. 1976. Crop water deficits. Advances in Agronomy 28: 161-217.

Blum, A. 2005. Drought resistance, water-use efficiency, and yield potential-are they compatible, dissonant, or mutually exclusive? Crop and Pasture Science 56: 1159-1168.

Blum, A. 2009. Effective use of water (EUW) and not water-use efficiency (WUE) is the target of crop yield improvement under drought stress. Field Crops Research 112: 119-123.

Blum, A. 2017. Osmotic adjustment is a prime drought stress adaptive engine in support of plant production. Plant, Cell and Environment 40: 4-10.

Cunningham, P.J.; Blumenthal, M.J.; Anderson, M.W.; Prakash, K.S.; Leonforte, A. 1994. Perennial ryegrass improvement in Australia. New Zealand Journal of Agricultural Research 37: 295-310.

Cyriac, D.; Hofmann, R.W.; Stewart, A.; Sathish, P.; Winefield, C.S.; Moot, D.J. 2018. Intraspecific differences in long-term drought tolerance in perennial ryegrass. Plos One 13: pp. 4.

Easton, H.S.; Baird, D.B.; Cameron, N.E.; Kerr, G.A.; Norriss, M.; Stewart, A.V. 2001. Perennial ryegrass cultivars: herbage yield in multi-site plot trials. Proceedings of the New Zealand Grassland Association 63: 183-188.

Garcia, L.F. 2015. Seleção de genótipos de azevém perene (Lolium perenne L.) com características de tolerâcia ao déficit hídrico. Bachelor of Animal Science Conclusion Thesis, Federal University of Mato Grosso, Brazil. (In Portugese).

He, L. 2016. Drought tolerance of perennial ryegrass (Lolium perenne L.) and the role of Epichloë endophyte. $\mathrm{PhD}$ thesis, Massey University.

Hussain, S. 2013. Drought resistance mechanisms in "Mediterranean" perennial ryegrass (Lolium perenne L.) and potential for introgression of "Mediterranean" germplasm into New Zealand commercial cultivars. 
$\mathrm{PhD}$ thesis, Massey University.

Kirkham, M.B. 2005. Principles of soil and plant water relations. Netherlands Academic Press, Amsterdam. $554 \mathrm{pp}$.

Lee J.M.; Matthew C.; Thom E.R.; Chapman D.F. 2012. Perennial ryegrass breeding in New Zealand: a dairy industry perspective. Crop and Pasture Science 63: 107-127.

Ludlow, M.M.; Muchow, R.C. 1990. A critical evaluation of traits for improving crop yields in water-limited environments. Advances in Agronomy, 43: 107-153.

Matthew, C.; Linden, A. van der; Hussain, S.; Easton, H.S.; Hatier, J.-H.B.; Horne, D.J. 2012. Which way forward in the quest for drought tolerance in perennial ryegrass? Proceedings of the New Zealand Grassland Association 74: 195-200.

Sartie, A.M.; Easton, H.S.; Matthew, C. 2009. Plant morphology differences in two perennial ryegrass cultivars. New Zealand Journal of Agricultural Research 52: 391-398.

Silsbury, J.H. 1961. A study of dormancy, survival and other characteristics in Lolium perenne L. at Adelaide, SA. Australian Journal of Agricultural Research 12: 1-9.
Serraj, R.; Sinclair, T.R. 2002. Osmolyte accumulation: can it really help increase crop yield under drought conditions? Plant, Cell and Environment 25: 333341.

Stewart, A. 2006. Genetic origins of perennial ryegrass (Lolium perenne) for New Zealand pastures. pp. 1120. In: Breeding for success: Diversity in action. Ed. Mercer, C.F. Proceedings of the 13th Australasian Plant Breeding Conference, Christchurch, New Zealand.

Thomas, H. 1990. Osmotic adjustment in Lolium perenne; its heritability and the nature of solute accumulation. Annals of Botany 66: 521-530.

Thomas, H.; Evans, C. 1989. Effects of divergent selection for osmotic adjustment on water relations and growth of plants of Lolium perenne. Annals of Botany 64: 581-587.

Tuberosa, R. 2012. Phenotyping for drought tolerance of crops in the genomics era. Frontiers in Physiology 3: 347 .

Vartha, E.W. 1975. Comparative annual and seasonal growth of three ryegrass varieties and cocksfoot at Lincoln, Canterbury. New Zealand Journal of Experimental Agriculture 3: 319-323. 